\title{
Need for innovations and reforms in pedagogy paradigm for transforming health professional education
}

\author{
Pandey, A.A. ${ }^{1}$, Sharma, A. ${ }^{2}$, Zodpey, S.P. ${ }^{2}$
}

\begin{abstract}
Health professionals are crucial elements of health systems which have a major impact on delivery of health outcomes. Efficient health professionals are a prerequisite to improve our health services. However, there has been a growing concern globally, about the mismatch of health professionals produced to the population needs and the need to bring reforms in health professional education. In the past, most attempts to revitalize health professional education have been restricted to changes in curriculum of health professional education, and the pedagogy techniques used remain more or less the same as used few decades ago. In view of the pressing need for changes in pedagogy techniques for health professional education; the present paper is an attempt to review the innovations and reforms in pedagogy in this field and suggest suitable recommendations. Currently, depending on the setting of the institutions where health professionals are trained, different pedagogical techniques are used and they can be categorized as Non IT \& IT enabled techniques. Although a wide range of pedagogy techniques are available, a large component of teaching and assessment is by traditional methods and there is need to expand the scope of use of various pedagogy techniques and use appropriate mix and match of methods. To facilitate this, there needs to be systemic and strategic changes, to give opportunities to faculty to develop skills in innovative teaching and to provide learning environments conducive to transformative learning. Also, there is need to conduct research on the use and impact of effective pedagogical methods.
\end{abstract}

Keywords: Health Professional Education, Pedagogy, Reforms, Transformative Learning

\section{Introduction}

Steered by the health professionals, the health workforce is one of the important building blocks of health systems (World Health Report, 2006). The core space of every health system is occupied by the unique encounter between the one set of people who need them and another who has been entrusted to deliver them (Frenk et al., 2010).

${ }^{1}$ National Guideline Alliance, Royal College of Obstetricians \& Gynaecologists, London, United Kingdom

${ }^{2}$ Public Health Foundation of India, New Delhi, India

Corresponding Author:

Dr. Anuja Pandey

Systematic Reviewer

National Guideline Alliance, Royal College of Obstetricians \& Gynaecologists, London, United Kingdom

E mail: anuja_2kn@yahoo.com
Efficient and well trained health professionals, equipped with competent technical expertise, ethical commitment and social orientation skills can help achieve better health services, and thus, optimum health outcomes. Cultivating this assortment of competencies requires finest training of the health professionals. However, there has been a growing concern globally, about the mismatch of health professionals produced to the population needs, in terms of both quantity and quality.

In 2004, Report of Joint Learning Initiative (JLI), an enterprise engaging more than 100 global health leaders in landscaping human resources for health, brought the agenda of role of human resources in health system on global centre stage. Following this, the agenda received further commitment with the establishment of the Global Health Workforce Alliance (2008) and the Asia Pacific Alliance on Human Resources of Health (AAAH).

DOI: http://doi.org/10.4038/seajme.v12i2.47

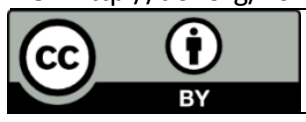

12

(C) SEAJME. This is an Open Access article distributed under the terms of the Creative Commons Attribution License (http://creativecommons.org/licenses/by/4.0/), which permits unrestricted use, distribution, and reproduction in any medium, provided the original author and source are credited.

Vol. 12, no. 2, 2018


The World Health Report 2006 further emphasized the need for developing capable, motivated and supported health workforce for overcoming bottlenecks to achieve national and global health goals. Focus on health professional education gained momentum with several initiatives across the globe to strengthen health systems by improving the quality and relevance of health workforce (Capacity Project 2009, WHO consultation on the transformative scale-up of medical, nursing and midwifery education 2010, PEPFAR's Medical \& Nursing Education Partnership Initiatives). Asia-Pacific Network on Health Professional Education Reform (ANHER), Increasing access to health workers in remote and rural areas through improved retention: global policy recommendations WHO 2010 and WHO Global Code of Practice on the International Recruitment of Health Personnel 2010). With the publication of WHO Transforming and Scaling up Health Professionals' Education Guidelines (2013), there was a call for policy and technical dialogue with key stakeholders on how to prepare health professionals for the 21st century by transforming health professional education. A new milestone was achieved by resolution on Transforming Health Workforce Education in support of Universal Health Coverage in World Health Assembly (WHA Resolution 66.23, 2013).

Apart from these ground breaking initiatives, several initiatives have been undertaken at regional and national levels to prepare a new generation of health professionals to address the challenges of ever changing health environment.

The need to approach health professional education in a systematic manner was directly raised by the Lancet report on Health Professionals for a New Century: Transforming Education to Strengthen Health Systems in an Interdependent World (2010). This landmark report, to advance the agenda of reforms in health professional education, has regarded transformative learning as the highest form of three levels of learning, moving from informative to formative to transformative learning. Health systems worldwide face growing demands of services and needs leaders who can motivate the health workforce to respond effectively to the unprecedented challenges. While informative learning produces experts and formative learning creates professionals; transformative learning produces change agents and leaders who can galvanize health system reforms.
As a proposed outcome of instructional reforms, transformative learning involves three fundamental shifts, from fact memorization to searching, analysis and synthesis of information for decision making, from seeking professional credentials to achieving core competencies for effective teamwork in health systems and from non-critical adoption of education models to adaptation of global resources to local priorities (Frenk et al., 2010). Transformative learning is a theory that challenges students' thinking and encourages using critical thinking and questioning the underlying assumptions and beliefs about the world (Howie, 2013). It is about developing leadership attributes: its purpose is to produce enlightened change agents who work effectively as teams in a health system and can use global resources to address local priorities. Transformative educators do not necessarily teach content that is remarkably different from more instrumentally oriented educators.

They may be found in the workplace, running a continuing education program, or teaching an adult education class. However, they teach the content with a different end in view, often using instructional strategies (Dirkx, 1998). Teaching strategies for fostering transformative learning may include questioning, case studies, storytelling, discussion, role-playing, simulations, peer education, reflection, interviews and collaborative learning. To bring the reforms in health professional education, transformative pedagogy is a necessitated entity that needs to be channeled in the teaching and training institutions (Zodpey \& Sharma, 2014).

While many steps have been taken to reform instructional methods to revitalize health professional education, most attempts have been restricted to changes to the course content of health professional education and despite the changes in course content and expected learning outcomes, the pedagogy techniques used remain more or less the same as used few decades ago.

Many institutions and educators are working hard at making improvements in teaching, but within the paradigm of routinely used pedagogy techniques. It is observed that though the stagnancy in education is contributed $70 \%$ by redundant teaching methods and $30 \%$ by outdated curricula, the changes in education system focus $70 \%$ on curriculum change and $30 \%$ on pedagogy methods. Evidence suggests that pedagogy 
techniques have a strong impact on learning outcomes (Westbrook et al., 2013). In view of the pressing need for changes in pedagogy techniques for health professional education; the present paper is an attempt to review the innovations and reforms in pedagogy in this field and suggest suitable recommendations.

\section{Pedagogy Techniques}

Health workforce include public health professionals (medical \& non-medical), dentists, nursing and midwifery professionals, doctors, traditional and complementary medicine professionals, ancillary staff, frontline workers and allied health professionals. Currently, depending on the setting of the institutions where health professionals are trained, different pedagogical techniques are used and they can be categorized as Non IT \& IT enabled techniques.

\section{Non IT Enabled techniques}

These include the traditional methods like lectures, workshops, seminars, panel discussions, conferences, questions and answers, group discussions, case studies, symposiums, tutorials, presentations, critical appraisals, field trips, debate, bulletin boards, research, project work, internships, mentorship, counseling, demonstrating \& collaborating and also newer and more interactive methods like problem based learning, buzz groups, brain storming, structured academic controversies, concept mapping, decision tree, fishbone, mind maps, multi age classrooms, Delphi technique, fishbowls, simulations and games, role play, process oriented guided enquiry lessons (POGIL), team based learning, project based learning and reality pedagogy.

The last century saw the evolution of innovative teaching methods with the gradual shift from "mere transfer of scientific information" to problem based learning. However, despite the introduction of many innovative techniques, their use is still not widespread and predominant mode of teaching across majority health professional institutions is still, through the traditional methods like lectures and demonstrations.

\section{IT Enabled Techniques}

With the advent of technology, there has been dispersion of technological innovations in health professional education and has been used to enhance learning. Some of the popular IT enabled teaching methods include flipped classrooms, Hip Hop Education, webinars, simulated activities, virtual field trips, web quests, real life data analysis, social classrooms and electronic mentoring.

Learning Management Systems (LMS) like Canvas, Moodle and Blackboard have not only helped in adding a new dimension to learning experience, but also helped tutors to organize all the resources students needed for a class, provide helpful assessment tools and create spaces for discussion and document/media sharing.

GradeCraft, a LMS developed at University of Michigan, has combined elements of gaming and learning together to let instructors organize their courses in a "gameful" way (Gradecraft, 2016). The concept of "edutainment" i.e. combining education with entertainment, is gaining popularity with the designing of courses based on popular television series (BBC News, 2016). Tools like Tegrity, Twittter, Facebook and clickers have all contributed in supporting as well as challenging the students. With the increase in use and ownership of smart phones, social media has gained attention, as an educational tool.

Researchers have observed that social media can support student engagement, collaboration and self-managed learning by creating platform for exchange of ideas and indepth discussion (Manca \& Ranieri, 2013). Effective use of social media promotes learning by facilitating communication and transfer of information (McLoughlin \& Lee, 2010). Technology has given genesis to a new platform for learning by offering courses which are completely online or a mix of online and classroom components, in the form of blended learning.

It has often been debated if technology enabled techniques are the answer to call for innovations to transform learning. Research suggests that merely introduction of technology, does not enhance student performance in terms of test scores, assignments and grades (Ni, 2012; Neuhauser, 2002 \& Pascarella, 2006).

It is also imperative not to treat technology enabled and "traditional" teaching as competing pedagogies, but rather they should be used in combination through mix and match of various pedagogical techniques. The choice of teaching method should depend on the 
skills to be acquired and expected learning outcomes. To achieve the outcomes of transformative learning, any universal instructional design may not be suitable. There is need to use an appropriate mix of suitable techniques. In some courses, this may involve intensive laboratory study, field work, projects, researching using original manuscripts available online or in a library. In others, learners may network with learners elsewhere in the world so as to gain the lens of different cultures or connect to others pursuing similar interests (Innovation Expedition, 2016). Attempts should be made to make learning as engaging as possible. Evidence suggests that student engagement is linked positively to desirable learning outcomes such as critical thinking, knowledge retention and transfer, and academic performance (Carini et al., 2006; Ewell, 2002; Klein et al., 2005 \& Korobova, 2012).

\section{Role of pedagogy in facilitating reforms}

Globally, health professionals are trained under various roofs and the instructional methods used may vary with the course, institute and the instructor. However, invariably, lecturing is the most widely used method across health professional institutes (Ildarabadi et al., 2014). Other common pedagogical techniques used in health professional education settings include demonstrations, presentations, field visits, question \& answers, piloting, discussions and case based learning (Lake, 2001 \& Nilsson et al., 2010).

Although, a number of innovative teaching methods have evolved and been used over the time, the significant focus of teaching is still on traditional pedagogical methods. Each pedagogical method has its unique strengths and weaknesses and it is critical that the health professional educators use the right mix and match of pedagogical techniques to effectively enhance the teaching from mere transfer of information to transformative learning.

In order to achieve the proposed outcome of transformative learning, the scope of use of pedagogical methods needs to be broadened. The enormous increase in the amount of accessible information through the internet calls for a reconsideration in the role of universities and educational institutions. The potential for learning has multiplied considerably, and this can be tapped by restructuring the methods of instruction, best suited to facilitate novel forms of learning beyond the realms of classrooms. This can be further supplemented by institutional reforms and there can be "pedagogy-driven discussion of the future of learning spaces".

Through a chain of events, flowing from effective learning to high quality services, to improved health, professional education at its best makes contribution for wellbeing of individuals, families and communities (Frenk et al., 2010). The extraordinary depth and breadth of knowledge/skills that is expected of health professionals today calls for faculty that are formally trained as health professional educators. It is worthy of note that though most health professional streams undergo professional certification, their teachers only need to demonstrate command over the subject rather than command over teaching before they appear in classrooms. Completion of a formal pedagogy course or demonstration of sufficient pedagogy skills is not an essential qualification for the job of teaching in health professional education institutes. As a result, the teachers often end up teaching what they learned from their experience as students. What holds widespread adoption of innovative pedagogy back is the lack of a requirement for training for college and university faculty in the art and science of teaching, the lack of investment in support for faculty for innovation, and the lack of collaborative sharing networks linked to disciplines of study (Innovation Expedition, 2016).

Health professionals are often required to work in a multidisciplinary team. Teaching institutes are an important place to begin learning with perspectives from other disciplines so that the health professionals are well adjusted to multidisciplinary environments. Team based learning with students from different streams can prepare health professionals for collaborative teamwork at workplaces.

There are opportunities for health professional educators to train themselves in teaching methods through short term trainings or long term courses, like Masters Programs in Health Professional Education/ Medical Education/ Clinical Education offered globally dedicated to building capacity of health professional educators (Tekian \& Harris, 2012). The Foundation for advancement of International Medical Education and Research (FAIMER) has been contributing to enhancement of educational opportunities for health professional educators through the International Fellowship in Medical Education 
(IFME) program, FAIMER institute and FAIMER regional institutes (FAIMER Organization, 2016). The National Faculty Development Programme by the Medical Council of India is also an attempt to build capacity of medical teachers in training and improve the quality of medical education $(\mathrm{MCl}$ India Organization, 2016).

However, such measures need to be taken across various disciplines of health professional education. Furthermore, time has come, to focus on the competencies addressed in the existing initiatives. The current scope of these initiatives is enhancing pedagogy using conventional methods. It is high time that the value of these opportunities is enhanced by incorporating methods to enhance teaching using the entire range of innovative methods. Capacity building of health professional educators needs to be taken up more systematically to implement reforms in pedagogy. It is important to build teacher capacity to build student capacity. Faculty support for developing innovative teaching methods is a key resource required to enhance teaching and learning.

There are potential challenges which need to be dealt with, to execute the reforms, like the relative lack of incentives for innovative teaching, Faculty members at universities are often - and rightly - acclaimed for their research, the impact of which can be measured relatively readily in citations, grant awards and opportunities to lecture to and write for the wider world. At the same time, their complex teaching responsibilities tend to receive far less public and even internal attention. At the same time, there is lack of opportunities for faculty to train themselves in innovative pedagogy. There needs to be systematic and strategic effort to create opportunities for faculty development in pedagogical techniques.

The attitude of academia towards teaching and learning also needs to change. It needs to be acknowledged that there is scope for improvement in teaching and there has to be hunger to learn about newer methods and passion to make learning more interactive, enjoyable and transformative. From systems point of view, it should be seen as an investment proposal in terms of faculty and more resources should be made available to facilitate instructional reforms. Another barrier to reforms is lack of adequate evidence on effective pedagogical methods in health professional education. Universities and
Institutions should engage in research in health professional education to advance this agenda.

WHO Guidelines for Transforming and Scaling up Health Professionals Education (2013) calls for a fundamental shift in the way health professional education is delivered. The expected learning outcomes needs to change from producing professionals with desired skill sets to producing change agents in health system. Health professionals not only need to have desired competencies, but they also need to be equipped with ability to adapt the core competencies to changing health system environment. This necessitates the professionalization of the health discipline's teaching component to bring a new era of instructional reforms to revolutionize health professional education.

\section{References}

Asia-Pacific Network on Health Professional Education Reform (ANHER), Available at: http://www.healthprofessionals21.org/index.php /news-views/asia [Accessed 4 Jun. 2016].

BBC News (2016) University launches online course with TV show - BBC News. [online] Available at: http://www.bbc.co.uk/news/ business -23931078 [Accessed 4 Jun. 2016].

Carini, R.M., Kuh, G.D. \& Klein, S.P. (2006) Student engagement and student learning: testing the linkages, Research in Higher Education, 47, 1, pp. 1-32.

Dirkx, J.M. (1998) Transformative learning theory in the practice of adult education: An overview. PAACE, Journal of lifelong Learning, 7, pp. 114. Available at: https://www.iup.edu/Work Area/DownloadAsset.aspx?id=18335 [Accessed 4 Jun. 2016].

Ewell, P.T. (2002) An Analysis of Relationships between NSSE and Selected Student Learning Outcomes Measures for Seniors Attending Public institutions in South Dakota, Boulder, CO: National Center for Higher Education Management Systems.

FAIMER.org (2016) FAIMER Education [online] Available at: $h t t p: / / w w w$. faimer.org/education /index.html [Accessed 5 Jun. 2016].

Frenk, J., Chen, L., Bhutta, Z.A., Cohen, J., Crisp, N., Evans, T., Fineberg, H., Garcia, P., Ke, Y., Kelley, P. \& Kistnasamy, B. (2010) Health professionals for a new century: transforming education to strengthen health systems in an interdependent world, The Lancet, 376, 9756, pp. 1923-1958. 
Global Health Workforce Alliance (2008) Scaling up, saving lives, Geneva: World Health Organization.

Gradecraft (2016) Gradecraft [online] Available at: http://www.gradecraft.com [Accessed 4 Jun. 2016].

Howie, P. \& Bagnall, R. (2013) A beautiful metaphor: Transformative learning theory, International Journal of Lifelong Education, 32, 6, pp. 816-836.

Ildarabadi, E., Karimi-Moonaghi, H., Heydari, A., Taghipour, A., Abdollahimohammad, A. \& Arbabisarjou, A. (2014) Teaching methods in community health nursing clerkships: experiences of health care staff in Iran, Journal of Educational Evaluation for Health Professionals, 11, pp. 25.

Innovation Expedition (2016) [online] Available at: http://www.innovationexpedition.com/emergingpedagogy-21st-century-learning/ [Accessed 4 Jun. 2016].

Joint Learning Initiative (2004) Human Resources for Health: Overcoming the Crisis, The Joint Learning Initiative, Cambridge: Harvard University Press. Available at: http://www.who. int/hrh/documents/JLi_hrh_report.pdf[Accessed 4 Jun 2016].

Klein, S.P., Kuh, G.D., Chun, M., Hamilton, L. \& Shavelson, R. (2005) An approach to measuring cognitive outcomes across higher education institutions, Research in Higher Education, 46, 3, pp. 251-276.

Korobova, N. (2012) A comparative study of student engagement, satisfaction, and academic success among international and American students, Graduate Theses and Dissertations. Paper, 12367.

Lake, D.A. (2001) Student performance and perceptions of a lecture-based course compared with the same course utilizing group discussion, Physical Therapy, 81, 3, pp. 896902.

Manca, S. \& Ranieri, M. (2013) Is it a tool suitable for learning? A critical review of the literature on Facebook as a technology-enhanced learning environment, Journal of Computer Assisted Learning, 29, 6, pp. 487-504.

MCIIndia.org (2016) National Faculty Development Programme [Online] Available at: http://www.mciindia.org/InformationDesk/ForCo lleges/NationalFacultyDevelopmentProgramme .aspx [Accessed 5 Jun. 2016].

McLoughlin, C. \& Lee, M.J. (2010) Personalised and self regulated learning in the Web 2.0 era: International exemplars of innovative pedagogy using social software, Australasian Journal of Educational Technology, 26, 1, pp. 28-43.
Neuhauser, C. (2002) Learning style and effectiveness of online and face-to-face instruction, The American Journal of Distance Education, 16, 2, pp. 99-113.

Nilsson, M., Pennbrant, S., Pilhammar, E. \& Wenestam, C. (2010) Pedagogical strategies used in clinical medical education: an observational study, BMC Medical Education, 10,1, p. 9.

Pascarella, E.T. (2006) How college affects students: Ten directions for future research, Journal of College Student Development, 47, 5, pp. 508-520.

Planning, developing and supporting the health workforce (2009) Results and lessons learned from the Capacity Project, 2004-2009. Washington, DC, USAID, 2009, Available at: http://www.capacityproject.org/images/stories/c apacity_project_final_report.pdf [Accessed 4 Jun. 2016].

Tekian, A. \& Harris, I. (2012) Preparing health professions education leaders worldwide: A description of masters-level programs, Medical Teacher, 34, 1, pp. 52-58.

The U.S. President's Emergency Plan for AIDS Relief. PEPFAR's Medical \& Nursing Education Partnership Initiatives. Available at: $h t t p: / / w w w$. pepfar.gov/partnerships/initiatives/index.htm [Accessed 4 Jun. 2016].

Westbrook, J., Durrani, N., Brown, R., Orr, D., Pryor, J., Boddy, J. \& Salvi, F. (2013) Pedagogy, curriculum, teaching practices and teacher education in developing countries, Education rigorous literature review, London, UK: Department for International Development (DFID).

World Health Organization (2006) The World Health Report 2006 - Working Together for Health, Geneva: World Health Organization.

World Health Organization (2010) Increasing access to health workers in remote and rural areas through improved retention: global policy

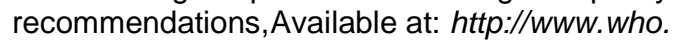
int/hrh/retention/guidelines/en/index.html [Accessed 4 Jun. 2016].

World Health Organization (2010) WHO consultation on the transformative scale-up of medical, nursing and midwifery education, Second technical reference group meeting: Nursing and midwifery education experts; 2010 July, Available at: http://www.who.int/hrh/ documents/education/en/ [Accessed 4 Jun. 2016].

World Health Organization (2010) WHO Global Code of Practice on the International Recruitment of Health Personnel, Available at: http://www.who.int/hrh/migration/code/WHO_gl obal_code_of_practice_EN.pdf [Accessed 4 Jun. 2016]. 
World Health Organization (2013) Transforming and scaling up health professionals' education and training, Geneva: World Health Organization.

$\mathrm{Ni}$, A.Y. (2012) Comparing the effectiveness of classroom and online learning: Teaching research methods, Journal of Public Administration Education, 19, 2, pp. 199-215.
Zodpey, S. \& Sharma, A. (2014) Advancing reforms agenda for health professionals' education through transformative learning, Indian Journal of Public Health, 58, 4, pp. 219. 